Perspective

\title{
Integrating GeoDesign with Landscape Sustainability Science
}

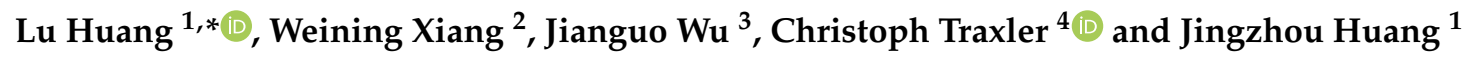 \\ 1 Smart City Research Center of Zhejiang Province, Hangzhou Dianzi University, Hangzhou 310012, China; \\ huangjz@hdu.edu.cn \\ 2 Department of Geography and Earth Sciences, University of North Carolina at Charlotte, Charlotte, \\ NC 28223, USA; wxiang@uncc.edu \\ 3 School of Life Sciences \& School of Sustainability, Arizona State University, Tempe, AZ 85287, USA; \\ Jingle.Wu@asu.edu \\ 4 VRVis Zentrum für Virtual Reality und Visualisierung Forschungs-GmbH, 1220 Vienna, Austria; \\ traxler@vrvis.at \\ * Correspondence: luhuang@hdu.edu.cn; Tel.: +86-158-6918-8627
}

Received: 27 December 2018; Accepted: 31 January 2019; Published: 5 February 2019

\begin{abstract}
With an increasing world population and accelerated urbanization, the development of landscape sustainability remains a challenge for scientists, designers, and multiple stakeholders. Landscape sustainability science (LSS) studies dynamic relationships among landscape pattern, ecosystem services, and human well-being with spatially explicit methods. The design of a sustainable landscape needs both landscape sustainability-related disciplines and digital technologies that have been rapidly developing. GeoDesign is a new design method based on a new generation of information technology, especially spatial information technology, to design land systems. This paper discusses the suitability of GeoDesign for LSS to help design sustainable landscapes. Building on a review of LSS and GeoDesign, we conclude that LSS can utilize GeoDesign as a research method and the designed landscape as a research object to enrich and empower the spatially explicit methodology of LSS. To move forward, we suggest to integrate GeoDesign with LSS from six perspectives: strong/weak sustainability, multiple scales, ecosystem services, sustainability indicators, big data application, and the sense of place. Toward this end, we propose a LSS-based GeoDesign framework that links the six perspectives. We expect that this integration between GeoDesign and LSS will help advance the science and practice of sustainability and bring together many disciplines across natural, social, and design sciences.
\end{abstract}

Keywords: GeoDesign; Landscape Sustainability Science; landscape design/planning; ecosystem services; information technology; evaluation

\section{Introduction}

Sustainability (sustainable development) is the theme of our time. However, our world today is replete with unsustainable villages, cities, and regions. To achieve sustainability from local to global scales, our landscapes and regions must be better designed and planned [1-3]. This requires sustainable landscape architecture [4], or sustainable landscape design. Landscape Sustainability Science (LSS), sustainability science at the landscape and regional scales, is an emerging transdisciplinary field that investigates the dynamic relationships among landscape pattern, ecosystem services, and human well-being with spatially explicit methods [2]. One of the main premises of LSS is "there must be some landscape configurations that are more desirable than others for improving and maintaining ecosystem services and human well-being" [2]. The identification and design of desirable landscape 
configurations is a central question in LSS. To accomplish this, LSS needs designing tools to "find" and design such configurations.

Most landscape design practices encounter one or more of the following issues: (1) The lack of real-time assessment. Assessment of design often takes place after designing. However, Building Information Modeling (BIM) realizes real-time assessment when designing a building. If such design methods as BIM can be applied to spatial design at broader scales, it will be possible to implement real-time assessment of landscape design. (2) The lack of dynamic analysis during design. Most designs are presented by graphs and tables in a static way, but today's advanced GIS technology has a great potential for data visualization. (3) The lack of public participation. A good design requires the combination of a top-down approach and a bottom-up approach. The latter can provide valuable information for setting up an appropriate design goal and optimizing a design solution $[5,6]$. Nowadays, however, the efficiency of participation is low and the cost is relatively high.

GeoDesign, as an effective instrument of landscape design, has emerged in recent decades, which analyzes, simulates, and designs geographic space with the support of geographical science and computer technology [7-9]. Compared with other landscape design methods, GeoDesign emphasizes the utilization of information technologies [7-11]. Internet of things, big data, cloud computing, virtual reality, and "human-computer" interaction could all be applied in GeoDesign. There is no consensus on the definition of GeoDesign. However, GeoDesign is ready to adopt new integrative science frameworks and advanced technologies, with a great potential for future applications of many kinds.

We are now in a time when technologies rapidly develop while sustainability becomes a global concern. To design a sustainable landscape, LSS needs a tool set for place-specific and use-inspired research. Is GeoDesign a fitting tool for LSS? How to integrate GeoDesign with LSS? These are the main research questions of this paper. Based on a review of LSS and GeoDesign, we will explain why GeoDesign is promising to extend the paradigm of LSS, and then demonstrate the promise by a showcase of GeoDesign applications. At last, we will propose a research agenda for further integrating GeoDesign and LSS.

\section{The Need of LSS for a Tool Set to Support Place-Based and Use-Inspired Research}

Landscape Sustainability Science (LSS) is a "place-based, use-inspired science of understanding and improving the dynamic relationship between ecosystem services and human well-being with spatially explicit methods" [2]. As an emerging field of study, it is based on three premises [2]. The first is that landscape pattern and landscape function (including flows of material, energy, and information) interact with each other, both of which affect the production and transfer of ecosystem services; the second is that ecosystem services are fundamentally important to human wellbeing; the third is that landscape sustainability can be enhanced by improving landscape patterns through design. Compared with the first two premises, much research is needed in the third area.

Design, linking human and landscape, can be used as a systems approach to connect social and ecological sciences for sustainability solutions [12] (Figure 1). In this design-in-science paradigm [13], science can identify a sustainable landscape only in dialogue with multiple stakeholders, offer multifunctional concepts (e.g., social-ecological systems, natural capital, ecosystem/landscape services, green infrastructure and ecological compensation) in the landscape medium, and ultimately, help seek "optimal" or "preferred" landscape patterns to create sustainable solutions. 


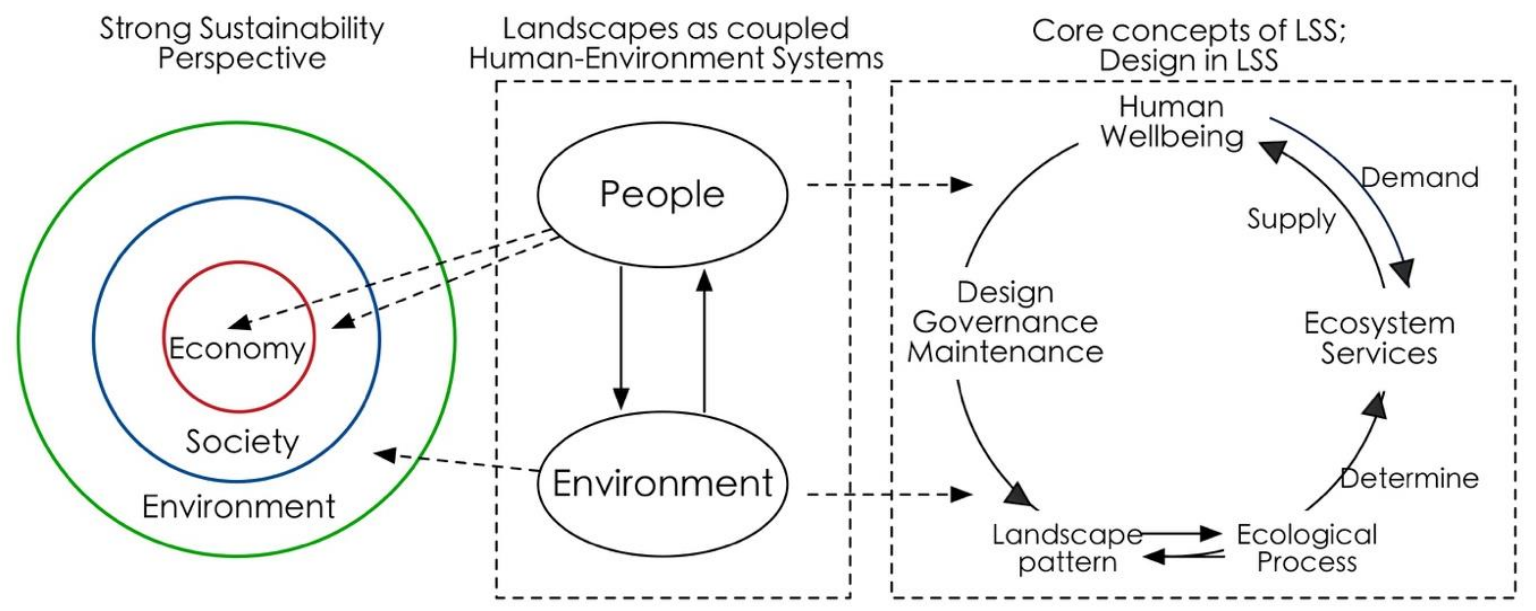

Figure 1. Core concepts of Landscape Sustainability Science (LSS) and the role of design in LSS (modified from [2]).

According to the LSS paradigm, a design or planning tool set is required to analyze, model, and test the relationships among spatial pattern, ecosystem services, and human wellbeing. The tool set must be spatially explicit and scalable. Since such "optimal" or "preferred" patterns will be inevitably dynamic, and the type and number of ecosystem services will vary among different types of landscapes in a specific region, the tool set should be able to conduct dynamic analysis, iterative modelling, and to evaluate interactions between design interventions and a variety of ecological conditions and ecosystem services. Besides, to create a sustainable landscape or region, the combination of top-down approach and bottom-up approach is essential. The tool set should enable multiple stakeholders to participate conveniently and efficiently.

\section{A Brief Review of Landscape Design Methods and Techniques}

The need of LSS for a tool set can be met by a range of landscape design methods and techniques. Based on Li and Milburn's work [14], we listed the main findings of science and techniques of landscape design from 1850s to present (Table 1). The first era was the analogue era (mid-19th century to mid-20th century). Hand drawing was the basic skill, and Warren Manning invented the map overlay method with a light table. Scientific theory, relatively weak, started to be combined with art. The second era was the poor data era (mid-20th century to 1970s). McHarg's map-overlay method was applied in land suitability analysis with the awareness of environmental protection. Digital data and computer-based GIS arose to satisfy the increasing need for decision support systems. The third era was the small data era (1970s-2000). During this period, environmental and ecological data increased, and science-based methods, digital modeling, and analysis techniques were also advanced. The development in the field of ecology supplemented design theories. The fourth era was the big data era (2000 to present). Ecological thinking has been gradually changing over to sustainability thinking. Meanwhile, high-resolution remote sensing data, Light Detection and Ranging, Global Positioning System technologies, and interactive drawing devices have been increasingly used for data collection and analysis. 
Table 1. Main scientific and technical developments of landscape design (organized based on [14]).

\begin{tabular}{|c|c|c|c|}
\hline Era & Science and Art & Technology & Tools \\
\hline $\begin{array}{l}\text { The analogue era (mid-19th century to } \\
\text { mid-20th century) }\end{array}$ & $\begin{array}{l}\text { - Frederick Law Olmsted Sr. } \\
\text { (1822-1903): the father of American } \\
\text { landscape architecture } \\
\text { - } \quad \text { Patrick Geddes (1854-1932): } \\
\text { "survey-analysis-design” process } \\
\text { - Warren Manning (1860-1938): map } \\
\text { overlays method with light table } \\
\text { - Frank Lloyd Wright } \\
\text { (1867-1959): Fallingwater }\end{array}$ & $\begin{array}{ll}\text { - } & \text { Large scope geological surveys } \\
\text { - } & \text { Remote sensing } \\
\text { - } & \text { Digital information and } \\
\text { electronic computation }\end{array}$ & $\begin{array}{l}\text { - } \quad \text { Mainly by hand sketching } \\
\text { - Map overlay method with } \\
\text { light table }\end{array}$ \\
\hline $\begin{array}{l}\text { The poor data era (mid-20th century to } \\
\text { 1970s) }\end{array}$ & $\begin{array}{l}\text { - The awareness of environmental } \\
\text { protection, e.g., Aldo Leopold, } \\
\text { Rachel Carson, environmental laws } \\
\text { and regulations } \\
\text { - Ian McHarg's map-overly land } \\
\text { suitability analysis }\end{array}$ & $\begin{array}{l}\text { - The emergence of digital data and } \\
\text { computer-based GIS }\end{array}$ & $\begin{array}{l}\text { Digital data and computed-based } \\
\text { GIS were limitedly used due to a } \\
\text { lack of digital data, low availability } \\
\text { of mainframe computers }\end{array}$ \\
\hline The small data era (1970s-2000) & $\begin{array}{ll}\text { - } & \text { Ecological planning, Human } \\
\text { ecological planning (Ian McHarg) } \\
\text { - } \quad \text { Ecological approach to landscape } \\
\text { planning (Frederick Steiner) } \\
\text { - } \quad \text { Human ecosystematic design (John } \\
\text { T. Lyle) } \\
\text { - Landscape planning (Carl Steinitz) }\end{array}$ & $\begin{array}{l}\text { - A variety of inventory and analysis } \\
\text { techniques arose } \\
\text { Digital modeling and analysis } \\
\text { methods were also advanced } \\
\text { Spatial operations allowed } \\
\text { designers to evaluate land use } \\
\text { suitability, landscape attractiveness, } \\
\text { and vulnerability, identify land use } \\
\text { conflicts, forecast population and } \\
\text { urban growth, and assess the } \\
\text { environmental and social impacts } \\
\text { of proposed changes }\end{array}$ & $\begin{array}{l}\text { - Data-driven analytical tools: GIS, } \\
\text { remote sensing software } \\
\text { Idea-driven computer graphic tools: } \\
\text { Auto-CAD, Photoshop, Illustrator, } \\
\text { 3D Studio Max }\end{array}$ \\
\hline
\end{tabular}


Table 1. Cont

\begin{tabular}{|c|c|c|c|}
\hline Era & Science and Art & Technology & Tools \\
\hline The big data era (2000 to present) & $\begin{array}{l}\text { Carl Steinitz's revised framework } \\
\text { of landscape planning: three major } \\
\text { iterations-understanding the study } \\
\text { area-specifying } \\
\text { methods-performing study } \\
\text { - Sustainable landscape ecological } \\
\text { planning, adaptive planning and } \\
\text { design (Jack Ahern) } \\
\text { Land system architecture (B.L. } \\
\text { Turner II) } \\
\text { Diagrammatic model to depict how } \\
\text { to sustain ecosystem services for } \\
\text { urban regions (Richard Forman and } \\
\text { Jianguo Wu) } \\
\text { Pasteur's quadrant as an appealing } \\
\text { ecophronetic alternative to the } \\
\text { present research in ecosystem } \\
\text { services (Weining Xiang) }\end{array}$ & $\begin{array}{l}\text { Information grow in volume, } \\
\text { variety and velocity } \\
\text { Exponential growth in data } \\
\text { requires novel approaches } \\
\text { Geospatial data has reached } \\
\text { unprecedented resolution levels } \\
\text { - Image processing methods have } \\
\text { been advanced } \\
\text { - Social networks and smart } \\
\text { handheld devices equipped with } \\
\text { GPS have been wide accepted }\end{array}$ & $\begin{array}{l}\text { - } \\
\text { - } \quad \text { Lub-meter level remote sensing } \\
\text { Light Detection and Ranging } \\
\text { (LiDAR) } \\
\text { - Global Positioning } \\
\text { - } \quad \text { Idea-driven technologies } \\
\text { - } \quad \text { interactive drawing devices } \\
\text { Novel devices and modalities: } \\
\text { additive manufacturing } \\
\text { (3D-printers) }\end{array}$ \\
\hline
\end{tabular}


Theoretical developments have continued to support a better understanding of the landscape as an interface between natural and cultural processes [15]. Ecological planning, landscape planning, and sustainable landscape ecological planning all provided frameworks to help address the designing challenges to achieve the intended goals [15-19] (Table 1). Among these design methods, sustainable landscape design is an adaptive process to understand flows of material, energy, and information through concerted ecological, economic, and social activities within and beyond the landscape scale [3]. The aim is to improve human wellbeing in a certain period on the basis of environmental protection. Based on the three Es of sustainability (environment, economics, and equity/society), Musacchio [20] proposed that another three Es (aesthetics, ethics, and experience) should also be considered for designing sustainable landscapes. Another term, "land system architecture," has been proposed [21-23] to expand the reach of landscape architecture beyond the urban built environments, develop the understanding of human-environment systems, account for spatial interaction-trade off consequences as affected by the structure of different types of land units, and consider more on scales [22,23]. Sustainable land system architecture delivers similar information as sustainable landscape design.

In the big data era, sustainable landscape design has been taken more seriously (Table 1). Steinitz has revised his framework of landscape planning of "six iterative steps" [9,18], which presents six questions in an informed, iterative, and participatory planning process. Each question is answered with a dedicated model: the representation model is proposed for "how should the context be described"; the process model for "how does the context operate"; the evaluation model for "is the current context working well"; the change model for "how might the context be altered"; the impact model for "what differences might the changes cause"; and the decision model for "how should the context be changed." Land system architecture considers the architecture of land systems as a major determinant of ecosystem function and the capacity to provide ecosystem services [23]. Ahern et al. [24] applied the concept of ecosystem services in adaptive urban planning and design, proposed an adaptive method to promote innovation via "safe-to-fail" design experiments, and suggested indicators to monitor ecosystem services provided by green infrastructure. Forman and $\mathrm{Wu}$ [1] used a diagrammatic model to depict how to sustain ecosystem services for cities/urban regions, in which a large natural or semi-natural land adjoining an urban area, a natural land on vegetated hillslopes, protected natural-ecosystem patches between a large protected area and the urban area, a ring of relatively large parks, and greenspaces within a city can all provide an array of environmental, social, and economic benefits. Xiang $[25,26]$ suggested an ecophronetic alternative to the present research in ecosystem services.

\section{GeoDesign Provides More Promises to Meet the Need}

If GeoDesign is defined as a design-related activity that changes the context of the surroundings [27], it will be too broad and this kind of practice can date back to ancient times. If it is narrowed down to a design and planning method informed by geographic science and expressed in Geographic Information System (GIS)-based simulations [8], we can trace the origin back to McHarg's "Design with Nature" [16] (Table 1). McHarg not only developed a systematic way to understand regional planning and design, which involved participation of scientists from multiple disciplines, but also overlaid maps from various disciplines, including physical, biological, and social sciences. During the same period, Laboratory for Computer Graphics (later known as the Laboratory for Computer Graphics and Spatial Analysis) was founded, making it more convenient to implement overlay analysis. Over the past fifty years, overlay mapping has become one of the most widely used methods in spatial planning/design. 
With the development of GIS and spatial related technologies, a variety of inventory and analysis methods arose after 1970s. The term GeoDesign first appeared in Klaus Kunzmann's paper "Geodesign: Chance oder Gefahr?" [28]. The Environmental Systems Research Institute (ESRI) has popularized the concept of GeoDesign to emphasize the design function in GIS, awakening the deep rooted yet seemingly lost idea of "design with nature" [29].

GeoDesign has been defined from different perspectives of related disciplines, including geographic information science, planning/design, and information technology (Table 2). Steinitz [9] defined GeoDesign as a new method that produces design proposals and simulates design impacts with the support of systems thinking and digital technology. ESRI treats GeoDesign as not only a new vision for design with geographic knowledge (as cited in [9]) but also an innovative thought process that helps create any entity in a geo-scape [27]. Some researchers emphasized tight relationships between science and art in GeoDesign [8,30]. From the perspective of science, it emphasizes how environmental systems and social systems operate; and from the perspective of art, it emphasizes creativity, individual experience, self-awareness, interpretation, and expression [8].

To clarify the definition of GeoDesign, we should notice that GeoDesign is not a science but a transdisciplinary field of research and practice supported by science and technology. In this paper, we consider GeoDesign as a new method for sustainable landscape design (or land system design), integrated with multiple supporting disciplines and new-generation information/digital technologies. The multiple disciplines include not only traditional space-related disciplines, i.e., urban planning, architecture, and landscape architecture, but also geography, sustainability science, ecology, sociology, economy, and information science. The new generation of information technology is represented by internet of things, big data, cloud computing, virtual reality, etc. The high-new spatial information technology includes sub-meter level remote sensing, light detection and ranging, global positioning system technologies, etc.

Accordingly, criteria for judging GeoDesign should also be clarified. Ervin [11] proposed 15 essential components of an ideal GeoDesign toolbox: Content/Base, Objects, Configuration, Constraints, Library, Collaboration, Versions, Abstraction, Diagrams, Hyperlinks, Models/Scripts, Time, Simulation, Dashboard, and Methods Coach. Any GeoDesign project should involve all these components to a certain degree. Muller and Flohr [7] proposed eight underlying principles of GeoDesign: reflective practice, innovation in digital tools, crossing disciplines, iterative modeling, performance assessment and accounting, use of high-resolution data, mixed spatial methods, and community engagement. By categorizing 28 GeoDesign practices, Tulloch [31] classified the practices into three types, which were involved with computer-assisted design, public participation, and mathematical models, respectively. According to the criteria mentioned above, GeoDesign involves at least the application of big data, virtual reality and high-new spatial information technology in the analysis, modeling, and assessment of the design process. Consequently, it will inevitably cover the following detailed contents, including database, abstraction, configuration, diagrams, iterative models, feedback, crossing disciplines, and collaboration. 
Table 2. Definitions of GeoDesign.

\begin{tabular}{|c|c|c|c|}
\hline Source & Definition & Key Points & Background of Discipline \\
\hline $\begin{array}{l}\text { Carl Steinitz (in GeoDesign Summit, } \\
\text { 2010) }\end{array}$ & GeoDesign is "geography by design". & A branch of geography & Planning \& Design \\
\hline $\begin{array}{l}\text { Michael Flaxman (in GeoDesign Summit, } \\
\text { 2010) }\end{array}$ & $\begin{array}{l}\text { GeoDesign is "a design and planning } \\
\text { method which tightly couples the } \\
\text { creation of design proposals with impact } \\
\text { simulations informed by geographic } \\
\text { contexts". }\end{array}$ & $\begin{array}{l}\text { A design and planning method; focusing } \\
\text { on evaluating and feedback }\end{array}$ & Planning \& Design \\
\hline Juan Vargas-Moreno [10] & $\begin{array}{l}\text { GeoDesign is "the act of integrating the } \\
\text { constantly transforming techniques, } \\
\text { concepts and approaches in design and } \\
\text { planning with GeoSpatial systems and } \\
\text { technologies". }\end{array}$ & $\begin{array}{l}\text { Integrating techniques in design and } \\
\text { planning }\end{array}$ & Planning \& Computing \\
\hline Michael Goodchild [8] & $\begin{array}{l}\text { GeoDesign is "a design and planning } \\
\text { method informed by scientific } \\
\text { knowledge of how the world works, } \\
\text { expressed in GIS-based simulations". }\end{array}$ & $\begin{array}{l}\text { A design and planning method, which } \\
\text { couples science and technology }\end{array}$ & The science of GIS \\
\hline $\begin{array}{l}\text { Carl Steinitz, Michael Flaxman and } \\
\text { Stephen Ervin [9] }\end{array}$ & $\begin{array}{l}\text { GeoDesign is "a design and planning } \\
\text { method which tightly couples the } \\
\text { creation of design proposals with impact } \\
\text { simulations influenced by geographic } \\
\text { contexts, system thinking, and digital } \\
\text { technology". }\end{array}$ & $\begin{array}{l}\text { Adding system thinking and digital } \\
\text { technology comparing to Michael } \\
\text { Flaxman (in GeoDesign Summit, 2010) }\end{array}$ & Planning \& computing \\
\hline $\begin{array}{l}\text { Jack Dangermond [as cited in [9], } \\
\text { Forward] }\end{array}$ & $\begin{array}{l}\text { GeoDesign is "a vision for using } \\
\text { geographic knowledge to actively and } \\
\text { thoughtfully design". }\end{array}$ & $\begin{array}{l}\text { Not only a planning method, but also a } \\
\text { new vision }\end{array}$ & GIS \\
\hline William Miller [27] & $\begin{array}{l}\text { GeoDesign is "the thought process } \\
\text { comprising the creation of an entity in } \\
\text { geo-scape". }\end{array}$ & $\begin{array}{l}\text { Extending "geo" to "geo-scape"; } \\
\text { defining design as a thought process }\end{array}$ & GIS \\
\hline
\end{tabular}


Table 2. Cont.

\begin{tabular}{|c|c|c|c|}
\hline Source & Definition & Key Points & Background of Discipline \\
\hline Michael Batty [30] & $\begin{array}{l}\text { "[U]sing science in design as well as } \\
\text { design in science, building on new and } \\
\text { powerful formalities as well as logical } \\
\text { chains of reasoning, predictions, and } \\
\text { prescription". }\end{array}$ & $\begin{array}{l}\text { Tight relationship between science and } \\
\text { design }\end{array}$ & Computing \\
\hline Stephen Ervin [11] & $\begin{array}{l}\text { GeoDesign is "environmental planning } \\
\text { and design usually involving large areas, } \\
\text { complex issues, and multi-person teams, } \\
\text { that leverages the powers of digital } \\
\text { computing, algorithmic processes, and } \\
\text { communication technologies to foster } \\
\text { collaborative, information-based design } \\
\text { projects, and that depends upon timely } \\
\text { feedback about impacts and implications } \\
\text { of proposals based on dynamic modeling } \\
\text { and simulation, and is informed by } \\
\text { systems thinking". }\end{array}$ & $\begin{array}{l}\text { Proposing essential components of } \\
\text { GeoDesign }\end{array}$ & Planning \& Computing \\
\hline Brian Muller and Travis Flohr [7] & $\begin{array}{l}\text { GeoDesign is "rooted in use of digital } \\
\text { technologies that integrate information } \\
\text { about social and natural systems as a } \\
\text { basis for modeling, analysis and } \\
\text { communication of design and plan } \\
\text { effects". }\end{array}$ & $\begin{array}{l}\text { System thinking; emphasis on the usage } \\
\text { of technology }\end{array}$ & Planning \& Design \\
\hline
\end{tabular}




\section{A Showcase of GeoDesign Applications}

The commonly used tools of GeoDesign can be classified into three types: (1) integrating spatial data analysis into traditional design software (e.g., ESRI's ArcCAD, and ArcGIS for Auto CAD), enabling designers to perform GIS analysis with the AutoCAD platform; (2) integrating design function into traditional GIS software (e.g., ESRI's ArcSketch provides the function of sketching surface features in ArcGIS environment, and CityEngine provides the function of 3D modeling based on rules and parameters in the ArcGIS environment); (3) assessment systems for design proposals, e.g., Vista in NatureServ, CommunityViz in Orton, INDEX in Criterion Planner, SSIM in AECOM, Whatif?2.0. Among all these tools, INDEX is a human-computer interactive planning support system based on ArcGIS that adopts multiple indicators from its database to quantitatively evaluate design proposals [7,32-34].

Adopting Steinitz's framework, researchers have developed a GeoDesign platform of GeodesignHub.com, which supports ten systems and six multidisciplinary design teams to provide GeoDesign for sustainable development of watershed in King County, Washington, for over 40 years [35]. Based on Steinitz's framework, "Automated Design Model" was developed to design wildlife corridors between Saguaro National Park East and West, US [36], a security pattern was incorporated to design Wulingyuan National Scenic Area, China [37], and CityEngine was employed to implement parametric design in Brazil [38]. In landscape and urban planning, GeoDesign has been integrated into collaborative design processes, combining people's demands and scientific methods (e.g., analysis of impacts of change, trade-off analysis of conflicting values) and visualizing the processes and results of design in GIS-based platform [39,40]. GeoDesign-related platforms have also been developed, such as "Tsinghua GeoDesign Platform," with which researchers can perform data collection, current status analysis, assessment, modeling, and presenting design solutions so as to support the whole urban planning process [34]. Spatial and morphological tools for GeoDesign have been developed to measure street-network configuration, building density, and functional mix [41]. The GEARViewer developed at the VRVis Research Centre in Austria focuses also on the impact of street and railway networks on a landscape or an urban environment [42,43]. It consists of an interactive $3 \mathrm{D}$ viewer that allows users to assess planned infrastructure projects, considering the effects of traffic volume, noise pollution, and occlusions. In GeoDesign applications, data availability is usually a limiting factor. Based on a pictorial approach and a touch screen, a Netherland team employed a qualitative method to develop a touch-screen app "Phoenix," which could help the public to participate in GeoDesign in a data-limited area [44].

\section{A Research Agenda for Moving Forward}

The ultimate goal of LSS is to optimize spatial pattern to improve human wellbeing, with spatially explicit approaches. GeoDesign, which extends the spatially explicit method, provides an excellent platform to model the impact of some variables on other variables under certain conditions. In this platform, visualization, real-time assessment, and feedback could help understand the relationships among spatial pattern, ecosystem services, and human wellbeing. Besides, GeoDesign includes dynamic analysis, systematic modeling, public participation, and multidisciplinary cooperation, all of which could enable LSS to be more practical [45], and make it a multi-dimensional discipline that transcends boundaries of natural and social sciences, and fully integrates theory and practice into a unified framework. To achieve the ultimate goal of LSS, GeoDesign can be integrated with LSS from the following six perspectives.

\subsection{Strong/Weak Sustainability}

Weak sustainability permits mutual substitutability between natural capital and human-made capital. According to weak sustainability, a system is sustainable as long as the total amount of capital stocks is not decreasing, even if the environment degrades. Except for neoclassical economists, 
most natural and social scientists believe in strong sustainability [46], i.e., human-made capital and natural capital basically complement each other, and environmental health is the foundation for both social and economic sustainability. The perspective of strong or weak sustainability exists in people's self-consciousness or subconsciousness. Hence, the perception of the leader of a designing project will have a great impact on the process and outcome of design. LSS advocates that, for coupled human-environment systems to achieve strong sustainability at the landscape or regional scale, it is often necessary to allow for weak sustainability at a smaller scale [2].

At the regional and global scales, strong sustainability should be the goal; while at local scales, weak sustainability is often necessary. GeoDesign is employed mostly at the meso-scale [47]. Both perspectives of strong and weak sustainability should be considered at the meso-scale, referring to landscape and regional scales on which LSS is focused. The consilience of scale ensures the integration of LSS and GeoDesign in studies.

\subsection{Multiple Scales}

Scale issues have been widely recognized in design and LSS. The scale in design often refers to spatial scale. Designing at a large scale, generally, is a "defensive design" [9] that focuses on the protection of environment and culture, takes the perspective of strong sustainability mostly, and is affected by laws and regulations. The public may not be able to readily tell the differences before and after design because environmental changes at a large scale tend to be slow and thus inappreciable within a short period of time. However, designing at a small scale, generally, is an "offensive design" [9] that often takes the perspective of weak sustainability, focuses on creating new contents according to the client's fondness and funds, and is more sensible to the public as it is visible to people [48].

Landscape sustainability is inherently multiple-scaled because landscapes are structured hierarchically in space and organization, and because key issues of concern, data accuracy, and research methods vary across different scales. If the characteristic scale, the scale at which a pattern or process typically operates, can be detected, it will provide a key to scaling and profound understanding of LSS problems. However, there are also other kinds of scales (e.g., the observation scale, the analysis/modeling scale, and the policy scale) [49], which are related to each other in various ways in GeoDesign. At the beginning of a design, we should clarify the problem of interest and the scale desired by clients. This scale often corresponds to the observation scale. Only when the scales of observation and analysis/modeling are properly chosen, may the characteristic scale of the design be detected correctly. And only when the scale of policy implementation is commensurate with the characteristic scale, may the policies be effective [49].

\subsection{Ecosystem Services}

Indicator-based assessment, valuation assessment, and integrated modelling are three main ways to assess ecosystem services supply [50]. Indicator-based assessment reveals ecological benefits to human beings, valuation assessment reflects the scarcity of ecosystem services, and integrated modelling addresses the complexity of interactions that lead to ecosystem services production and delivery. Although all the three approaches can be used at any scale, indicator assessment can be used to quickly gauge the state and its changes of "ecosystem structure-ecosystem function-ecosystem services" on macro-scales while valuation assessment can be effective on micro-scales at which the replacement of natural capital with human-made capital is often necessary. Integrated models are suitable for macro-scale and meso-scale issues as the parameters needed in models are land use and cover, hydrology, and aerography related data.

Three functions need to be considered in designing sustainable landscapes: the production of goods and services that generate economic benefits, the provision of life enrichment services, and the ecological conservation [4]. These functions could be assessed by indicators for the provisioning services, cultural services, and regulating services, respectively. They can also be simulated by models 
depicting biophysical services (e.g., Integrated Valuation of Ecosystem Services and Tradeoffs, InVEST) and cultural services (e.g., Social Values for Ecosystem Services, SolVES).

Cumming et al. [51] pointed out that "one of the central problems of landscape sustainability is that of aligning the scale of demand for ecosystem services with the scale at which ecosystem service can be sustainably provided." Different areas often have different demands for ecosystem services. In GeoDesign, research on ecosystem services demand should be carried out considering local characteristics. From the perspective of strong sustainability perspective, human demands for ecosystem services should be met without degrading critical natural capital (i.e., the part of the natural environment with important environmental functions that cannot be replaced by human-made capital [52]. The determination of ecosystem services demand needs data from multiple sources. Remote sensing data (e.g., composite night light data), social-economic data (combining traditional statistic data and big data), and land use and cover data all provide information to capture actual demands for ecosystem services.

\subsection{Sustainability Indicators}

Indicators are widely used in design because of its indicative function, flexibility, and policy relevance. Sustainability indicators consider environmental, social, and economic dimensions, and can be divided into single composite indices and indicator sets according to the degree of aggregation [53]. Among single composite indices, Ecological Footprint, Environmental Performance Index, and Green City Index are strong sustainability indices; and City Development Index, Genuine Progress Indicator, Genuine Savings, Happy Planet Index, Human Development Index, Sustainable Society Index, and Wellbeing Index are weak sustainability indices. Among indicator sets, "Pressure-State-Response"-based indicator sets and material and energy flow indicator sets are strong sustainability indices, while theme-based indicator sets usually are weak sustainability indices.

The indicators above can assess historical and current situations of a design plot, monitor design process, and compare design alternatives. Evaluating current situation is relatively simple, while comparing the alternatives needs scenario analysis. Scenario is a future state portrayed by an array of characteristics in quality or quantity, indicating an approach developed from current situation. Scenario analysis does not answer "what is future like" but reflects possibilities of the future. Hence the aim of scenario analysis is to understand uncertainties, instead of predicting the future, so as to make efficient decisions in different scenarios [54,55]. In GeoDesign, it will be of great significance to choose proper characteristic indicators to depict the future and appropriate sustainability indicators to assess the future.

\subsection{Application of Big Data}

From the perspective of data availability and data analysis, GeoDesign is a process of data collection, analysis, and feedback. Increasing data availability and quality facilitate the development of design. Especially in the big data era, as information grows in volume, variety and velocity, novel approaches drive all branches of science and society to explore the potential of human knowledge and informed decisions enhanced by effective technologies (Table 1).

Big data from multiple sources, like environmental data or social-economic data, imply an approach that could mine from large volumes of data to better understand the properties of complex systems [56]. Nowadays, the collection and analysis of social-economic data have been done at a faster pace than those of environmental data, since the former is more related to personal life. With decreasing cost of devices of internet of things, big data from ecological and environmental respects will be increasingly used in GeoDesign. However, due to the paucity of culture of data curation and sharing, large volumes of data from diverse individual projects fail to contribute [57]. In the information age, scientists are increasingly required to bring their distributed data to the table and harness their collective power. 


\subsection{The Sense of Place}

Sense of place, providing landscapes with a unique spatial identity, can foster pro-environmental behaviors, and motivate people to protect places that are meaningful to them [58]. If a landscape design increases ecological quality but fails to arouse local people's care for the landscape, the design may not be appreciated or maintained. On the other hand, if it can arouse local people's care, the design would solidify environmental protection and facilitate sustainability $[59,60]$. Accordingly, GeoDesign, also for other designs, needs the understanding of sense of place, which emphasizes the significance of local culture. However, as Nassauer pointed out that "cultural concepts of nature are different from scientific concept of ecological function" [61], and cultural bias is not necessarily related to ecosystem function. A landscape aesthetically pleasing may not increase ecosystem services; and a design representing high ecosystem services may not be preferred by local people [62]. Designing orderly frames, by multiple "cues to care", is "one way of using the vernacular language of landscape to create greater ecological quality" [60].

Landscape is a multi-scale, multi-dimensional, and multi-functional spatial unit. Culture plays an important role in formatting and shaping landscapes [63]. Although Forman and Godron [64] pointed out, more than 30 years ago, that we must consider both the biophysical and sociocultural dimensions in order to understand a landscape, landscape ecology has not focused on culture despite its importance to the field [59]. In ecosystem services research, cultural services, i.e., the aesthetic, recreational, educational, therapeutic, and spiritual services that ecosystems bring to people, have been much less studied than provisioning and regulating services, although they are all important to human wellbeing. Until now, quantifying cultural services is still a great challenge, but substantial progress is being made [65]. Integration of cultural services into design is urgently needed with clear definition, evaluation, and modeling.

\subsection{A Conceptual Framework of Sustainable Landscape Design}

To advance the integration of GeoDesign with LSS, we propose a conceptual framework of sustainable landscape design, covering the six perspectives (Figure 2). The main body of the framework includes seven elements: (1) Problem determination and goal setting, (2) Pattern and process analysis, (3) GeoDesign platform construction, (4) Comprehensive simulation of ecosystem services and spatial pattern, (5) Visualization, (6) "Human-computer" interaction, and (7) Design alternatives assessment. The first four elements form the core of the framework, aiming to build quantitative relationships between ecosystem services supply and spatial structure variables. Then ecosystem services supply, fulfilling ecosystem services demand, will be changed in different spatial structures.

Among the six perspectives, the scale concept and strong/weak sustainability perspective run through the framework (Figure 2), depending on what problem designers face and what strategies designers take. The adoption of different scales or sustainability perspectives may lead to completely different results. The relationships between spatial pattern and ecosystem services can help choose optimal or preferred landscape patterns during design. The difficulty of applying ecosystem services in GeoDesign lies in the difference between the potential supply and realized supply of ecosystem services, the trades-offs and synergies among ecosystem services, and the linkages between ecosystem services and human wellbeing. Sustainability indicators, strongly related to strong/weak sustainability perspective and scale, can be used for assessment before, during, and after design. If the indicators are parameterized and presented by "human-computer" interaction, dynamic feedback can be realized in GeoDesign. Big data have been used in data management and demand analysis of ecosystem services. For example, it can capture open-access data, analyze word frequency, and then understand the public's needs for ecosystem services. The application of big data needs novel algorithms. The volume, variety, and velocity of data may have great impacts on results. Considering culture in the relationships among environment, society, and economics will further influence every step of the framework. Before integrating culture and sense of place into design, clear definition, evaluation, and modeling are needed. 

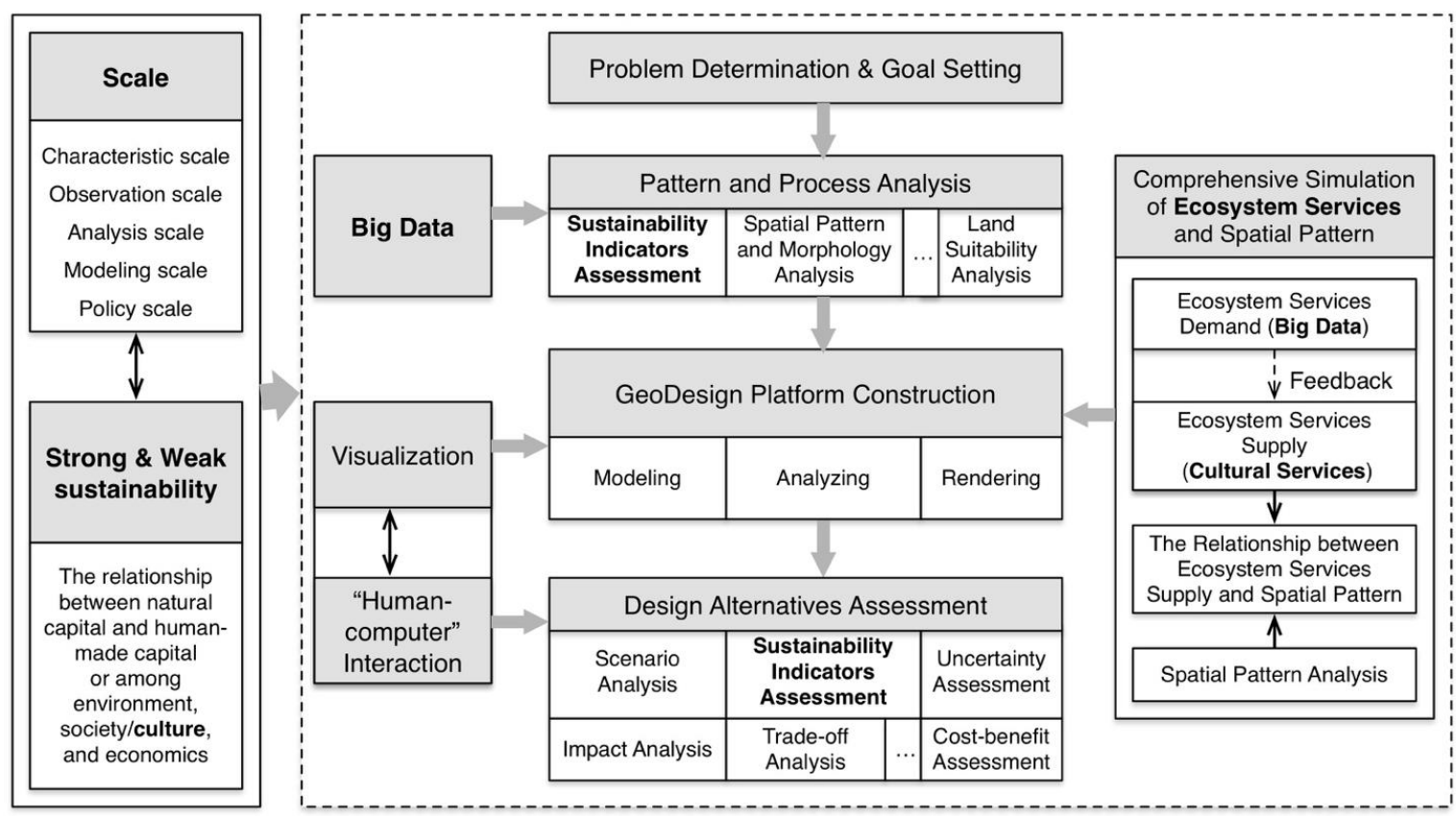

Figure 2. A conceptual framework of LSS-based GeoDesign with support of visualization and interaction technologies, as well as six perspectives (in boldface).

\section{Concluding Remarks}

As a transdisciplinary field, LSS aims to understand and improve the relationship between ecosystem services and human wellbeing mainly through optimizing landscape composition and configuration. Among all the methods and techniques of landscape design, GeoDesign is a rapidly developing design method based on advanced technologies, which has potential to break new grounds in the design industry. LSS can benefit greatly from GeoDesign as a research method, enhancing its spatially explicit analysis capacity and boosting its interactions with sustainable landscape/land system design.

Since LSS is a "use-inspired" science, the integration of GeoDesign with LSS needs more, or even extra, attention to "use". Data preparation, model building, projection and evaluation all cause uncertainties in landscape planning/design [55]. In addition to these technical issues, human aspects, like institutional bias, lack of analytical rigor, personal advocacy and unrealistic expectations of technology [66], need to be explicitly noted during any GeoDesign practice. This of course is hardly a new challenge, but it is imperative to the success of LSS/GeoDesign enterprise.

GeoDesign, as a high-tech approach, can work if models inside GeoDesign are built and applied by specialists who are familiar with the models and the planning/design problems. However, GeoDesign is not a panacea. Knowledge of why and how GeoDesign works is a must, so is the understanding of GeoDesign's possible limitations. One of the limitations is the paucity of frameworks that make the procedure of GeoDesign logical and integrative, which is a main impetus for our proposed LSS-based GeoDesign framework. The major purpose of integrating GeoDesign and LSS is to provide insights into landscape patterns, ecological consequences, and their interactions, which in turn can be used to guide the development of effective designs and decisions. Our science-based and application-oriented sustainable landscape design framework can facilitate multidisciplinary interaction, real-time evaluation, information technology application, and multi-stakeholder participation. It provides a starting point to integrate LSS and GeoDesign, and we hope to see more follow-up studies to further this endeavor in years to come.

Author Contributions: L.H. performed the literature review and wrote the first draft of the manuscript. J.W., W.X., C.T., and J.H. contributed to the review of the article, and to the final edit. 
Funding: This research was funded by the National Natural Science Foundation of China (grant number 41701638) and the Hangzhou Science and Technology Development Plan (grant number 20170834M30).

Acknowledgments: We would like to thank three anonymous reviewers, and Bingbing Zhou for their valuable comments and suggestions.

Conflicts of Interest: The authors declare no conflict of interest.

\section{References}

1. Forman, R.T.T.; Wu, J.G. Where are the best places for the next billion people? Think globally, plan regionally. In Handbook on Biodiversity and Ecosystem Services in Impact Assessment; Geneletti, D., Ed.; Edward Elgar Publishing: Cheltenham, UK, 2016.

2. Wu, J.G. Landscape sustainability science: Ecosystem services and human well-being in changing landscapes. Landsc. Ecol. 2013, 28, 999-1023. [CrossRef]

3. Wu, J.G. Urban ecology and sustainability: The state-of-the-science and future directions. Landsc. Urban Plan. 2014, 125, 209-221. [CrossRef]

4. Chen, $\mathrm{X} . ; \mathrm{Wu}, \mathrm{J}$. Sustainable landscape architecture: Implications of the Chinese philosophy of "unity of man with nature" and beyond. Landsc. Ecol. 2009, 24, 1015-1026. [CrossRef]

5. Eikelboom, T.; Janssen, R. Comparison of Geodesign Tools to Communicate Stakeholder Values. Group Decis. Negot. 2015, 24, 1065-1087. [CrossRef]

6. Sieber, R. Public Participation Geographic Information Systems: A Literature Review and Framework. Ann. Assoc. Am. Geogr. 2006, 96, 491-507. [CrossRef]

7. Muller, B.; Flohr, T. A Geodesign approach to environmental design education: Framing the pedagogy, evaluating the results. Landsc. Urban Plan. 2016, 156, 101-117. [CrossRef]

8. Goodchild, M.F. Towards geodesign: Repurposing cartography and GIS? Cartogr. Perspect. 2010, 66, 7-22. [CrossRef]

9. Steinitz, C. A Framework for Geodesign: Changing Geography by Design; ESRI: Redlands, CA, USA, 2012.

10. Vargas-Moreno, J.C. GeoDesign: The Emergence of a Tight-coupling Approach in GIS and Spatial Planning. Plan. Technol. Today 2010, 6-7.

11. Ervin, S.M. Technology in geodesign. Landsc. Urban Plan. 2016, 156, 12-16. [CrossRef]

12. Opdam, P.; Luque, S.; Nassauer, J.; Verburg, P.H.; Wu, J. How can landscape ecology contribute to sustainability science? Landsc. Ecol. 2018, 33, 1-7. [CrossRef]

13. Nassauer, J.I.; Opdam, P. Design in science: Extending the landscape ecology paradigm. Landsc. Ecol. 2008, 23, 633-644. [CrossRef]

14. Li, W.; Milburn, L.-A. The evolution of geodesign as a design and planning tool. Landsc. Urban Plan. 2016, 156, 5-8. [CrossRef]

15. Ahern, J. Theories, methods and strategies for sustainable landscape planning. In From Landscape Research to Landscape Planning: Aspects of Integration, Education and Application; Tress, B., Tress, G., Fry, G., Opdam, P., Eds.; Springer: Dordrecht, The Netherlands, 2005.

16. McHarg, I.L. Design with Nature; Natural History Press: Garden City, NY, USA, 1969.

17. Steiner, F. The Living Landscape: An Ecological Approach to Landscape Planning, 2nd ed.; McGraw-Hill: New York, NY, USA, 2000.

18. Steinitz, C. A framework for planning practice and education. In Ecological Landscape Planning; Bunji, M., Ed.; Process Architecture: Tokyo, Japan, 1995; pp. 42-54.

19. Panagopoulos, T.; Gonzalez Duque, J.A.; Bostenaru Dan, M. Urban planning with respect to environmental quality and human well-being. Environ. Pollut. 2016, 208, 137-144. [CrossRef] [PubMed]

20. Musacchio, L.R. The scientific basis for the design of landscape sustainability: A conceptual framework for translational landscape research and practice of designed landscapes and the six Es of landscape sustainability. Landsc. Ecol. 2009, 24, 993-1013. [CrossRef]

21. Turner, B.L. Sustainability and forest transitions in the southern Yucatán: The land architecture approach. Land Use Policy 2010, 27, 170-179. [CrossRef]

22. Turner, B.L., II. Land system architecture for urban sustainability: New directions for land system science illustrated by application to the urban heat island problem. J. Land Use Sci. 2016, 11, 689-697. [CrossRef] 
23. Turner, B.L., II; Janetos, A.C.; Verburg, P.H.; Murray, A.T. Land system architecture: Using land systems to adapt and mitigate global environmental change. Glob. Environ. Chang. 2013, 23, 395-397. [CrossRef]

24. Ahern, J.; Cilliers, S.; Niemelä, J. The concept of ecosystem services in adaptive urban planning and design: A framework for supporting innovation. Landsc. Urban Plan. 2014, 125, 254-259. [CrossRef]

25. Xiang, W.-N. Doing real and permanent good in landscape and urban planning: Ecological wisdom for urban sustainability. Landsc. Urban Plan. 2014, 121, 65-69. [CrossRef]

26. Xiang, W.-N. Pasteur's quadrant: An appealing ecophronetic alternative to the prevalent Bohr's quadrant in ecosystem services research. Landsc. Ecol. 2017, 32, 2241-2247. [CrossRef]

27. Miller, W.R. Introducing Geodesign: The Concept; ESRI: Redlands, CA, USA, 2012.

28. Kunzmann, K.R. Geodesign: Chance oder Gefahr. In Planungskartographie und Geodesign; Bundesforschungsanstalt fuer Landeskunde und Raumordnung: Bonn, Germany, 1993; Volume 7, pp. 389-396.

29. Dangermond, J. Jack Dangermond Talks about GeoDesign at TED 2010: Esri Video. 2010. Available online: http: / /video.esri.com/watch/125/jack-dangermond-talks-about-geodesign-at-ted2010 (accessed on 2 February 2019).

30. Batty, M. Defining geodesign (=GIS plus design?). Environ. Plan. B Plan. Des. 2013, 40, 1-2. [CrossRef]

31. Tulloch, D. Toward a working taxonomy of geodesign practice. Trans. GIS 2017, 21, 635-646. [CrossRef]

32. Flaxman, M. Fundamentals of geodesign. Proc. Digit. Landsc. Archit. Anhalt Univ. Appl. Sci. 2010, 2, $28-41$.

33. Chen, J.; Dang, A.; Xu, H. The application of Geodesign in Wuxi railway conceptual planning. Landsc. Archit. 2015, 3, 24-30. (available on 2 February 2019)(In Chinese) [CrossRef]

34. Zhou, W.; Yang, X.; Su, W. Development of GeoDesign platform and its application in urban planning. Chin. Landsc. Archit. 2015, 10, 12-17. (In Chinese)

35. Nyerges, T.; Ballal, H.; Steinitz, C.; Canfield, T.; Roderick, M.; Ritzman, J.; Thanatemaneerat, W. Geodesign dynamics for sustainable urban watershed development. Sustain. Cities Soc. 2016, 25, 13-24. [CrossRef]

36. Perkl, R.M. Geodesigning landscape linkages: Coupling GIS with wildlife corridor design in conservation planning. Landsc. Urban Plan. 2016, 156, 44-58. [CrossRef]

37. Huang, G.; Zhou, N. Geodesign in Developing Countries: The example of the Master Plan for Wulingyuan National Scenic Area, China. Landsc. Urban Plan. 2016, 156, 81-91. [CrossRef]

38. Moura, A.C. Geodesign in Parametric Modeling of Urban Landscape. Cartogr. Geogr. Inf. Sci. 2015, 42, 323. [CrossRef]

39. Hayek, U.W.; von Wirth, T.; Neuenschwander, N.; Gret-Regamey, A. Organizing and facilitating Geodesign processes: Integrating tools into collaborative design processes for urban transformation. Landsc. Urban Plan. 2016, 156, 59-70. [CrossRef]

40. Slotterback, C.S.; Runck, B.; Pitt, D.G.; Kne, L.; Jordan, N.R.; Mulla, D.J.; Zerger, C.; Reichenbach, M. Collaborative Geodesign to advance multifunctional landscapes. Landsc. Urban Plan. 2016, 156, 71-80. [CrossRef]

41. Ye, Y.; Yeh, A.; Zhuang, Y.; van Nes, A.; Liu, J. “Form Syntax” as a contribution to geodesign: A morphological tool for urbanity-making in urban design. Urban Des. Int. 2017, 22, 73-90. [CrossRef]

42. Mantler, S.; Hesina, G.; Greiner, M.; Purgathofer, W. GEARViewer: A State of the Art Real-Time Geospatial Visualization Framework. In Proceedings of the REAL CORP 2011, Essen, Germany, 18-20 May 2011; pp. 345-354.

43. Wickenhauser, K.; Hesina, G.; Traxler, C.; Greiner, M. Geospatial Visualization of Large Infrastructure Projects. In Proceedings of the 2nd International Symposium on Virtual Reality \& Visual Computing, Tianjin, China, 26-27 September 2017.

44. Janssen, R.; Dias, E. A pictorial approach to geodesign: A case study for the Lower Zambezi valley. Landsc. Urban Plan. 2017, 164, 144-148. [CrossRef]

45. Lenzholzer, S.; Duchhart, I.; Koh, J. 'Research through designing' in landscape architecture. Landsc. Urban Plan. 2013, 113, 120-127. [CrossRef]

46. Daly, H.E. Georgescu-Roegen versus Solow/Stiglitz. Ecol. Econ. 1997, 22, 261-266. [CrossRef]

47. Steinitz, C. On change and geodesign. Landsc. Urban Plan. 2016, 156, 23-25. [CrossRef]

48. Von Haaren, C.; Warren-Kretzschmar, B.; Milos, C.; Werthmann, C. Opportunities for design approaches in landscape planning. Landsc. Urban Plan. 2014, 130, 159-170. [CrossRef] 
49. Wu, J.G.; Jones, K.B.; Li, H.B.; Loucks, O.L. Scaling and Uncertainty Analysis in Ecology: Methods and Applications; Springer: Dordrecht, The Netherlands, 2006.

50. Mao, Q.; Huang, G.; Wu, J. Urban ecosystem services: A review. Chin. J. Appl. Ecol. 2015, 26, 1023-1033.

51. Cumming, G.; Olsson, P.; Chapin, F.S., III; Holling, C.S. Resilience, experimentation, and scale mismatches in social-ecological landscapes. Landsc. Ecol. 2013, 28, 1139-1150. [CrossRef]

52. Ekins, P. Identifying critical natural capital-Conclusions about critical natural capital. Ecol. Econ. 2003, 44, 277-292. [CrossRef]

53. Huang, L.; Wu, J.; Yan, L. Defining and measuring urban sustainability: A review of indicators. Landsc. Ecol. 2015, 30, 1175-1193. [CrossRef]

54. Boyko, C.T.; Gaterell, M.R.; Barber, A.R.G.; Brown, J.; Bryson, J.R.; Butler, D.; Caputo, S.; Caserio, M.; Coles, R.; Cooper, R.; et al. Benchmarking sustainability in cities: The role of indicators and future scenarios. Glob. Environ. Chang. 2012, 22, 245-254. [CrossRef]

55. Neuendorf, F.; von Haaren, C.; Albert, C. Assessing and coping with uncertainties in landscape planning: An overview. Landsc. Ecol. 2018, 33, 861-878. [CrossRef]

56. LaDeau, S.L.; Han, B.A.; Rosi-Marshall, E.J.; Weathers, K.C. The Next Decade of Big Data in Ecosystem Science. Ecosystems 2017, 20, 274-283. [CrossRef]

57. Hampton, S.E.; Strasser, C.A.; Tewksbury, J.J.; Gram, W.K.; Budden, A.E.; Batcheller, A.L.; Duke, C.S.; Porter, J.H. Big data and the future of ecology. Front. Ecol. Environ. 2013, 11, 156-162. [CrossRef]

58. Arts, B.; Buizer, M.; Horlings, L.; Ingram, V.; van Oosten, C.; Opdam, P. Landscape Approaches: A State-of-the-Art Review. Annu. Rev. Environ. Resour. 2017, 42, 439-463. [CrossRef]

59. Nassauer, J.I. The appearance of ecological systems as a matter of policy. Landsc. Ecol. 1992, 6, $239-250$. [CrossRef]

60. Nassauer, J.I. Messy ecosystems, orderly frames. Landsc. J. 1995, 14, 161-170. [CrossRef]

61. Nassauer, J.I. Culture and changing landscape structure. Landsc. Ecol. 1995, 10, 229-237. [CrossRef]

62. Gobster, P.H.; Nassauer, J.I.; Daniel, T.C.; Fry, G. The shared landscape: What does aesthetics have to do with ecology? Landsc. Ecol. 2007, 22, 959-972. [CrossRef]

63. Wu, J.G. Integrating nature and culture in landscape ecology. In Landscape Ecology in Asian Cultures; Hong, S.-K., Wu, J.G., Kim, J.-E., Nakagoshi, N., Eds.; Springer: Tokyo, Japan, 2011; pp. 301-321.

64. Forman, R.T.T.; Godron, M. Landscape Ecology; Wiley: New York, NY, USA, 1986.

65. Plieninger, T.; Bieling, C.; Fagerholm, N.; Byg, A.; Hartel, T.; Hurley, P.; López-Santiago, C.A.; Nagabhatla, N.; Oteros-Rozas, E.; Raymond, C.M.; et al. The role of cultural ecosystem services in landscape management and planning. Curr. Opin. Environ. Sustain. 2015, 14, 28-33. [CrossRef]

66. Barber, K.H.; Rodman, S.A. FORPLAN: The Marvelous Toy. J. For. 1990, 88, 26-30. 